\title{
Automated Timetable Generator
}

\author{
Yash Lahoti ${ }^{1}$, Aaditya Punekar ${ }^{2}$, Hiten Patel $^{3}$, Vishal Bhimsariya $^{4}$ \\ ${ }^{1,2,3,4}$ Computer Engineering Department, Thakur Polytechnic, Mumbai, India
}

\begin{abstract}
Most colleges have number of different courses and each course has a number of subjects. Now there are limited faculties, each faculty teaching more than one subjects. So now the time table needed to schedule the faculty at provided time slots in such ways that their timings do not overlap and the time table schedule makes best use of all faculty subject demands. We use genetic algorithm for this purpose. In our Timetable Generation algorithm we propose to utilize a timetable object. This object comprises of Classroom objects and the timetable for them likewise a fitness score for the timetable. Fitness score relates to the quantity of crashes the timetable has regarding alternate calendars for different classes. Classroom-object comprises of week objects. Week objects comprise of Days, Days also comprises of Timeslots. Timeslot has an address in which a subject, student gathering and going to the address and educator showing that the subject is related. Also further on discussing the imperatives, we have utilized composite configuration design, which make it well extendable to include or uproot as numerous obligations.In every obligation class the condition as determined in the inquiry is now checked between two timetable objects. On the off chance that condition is fulfilled i.e. there is a crash is available then the score is augmented by one.
\end{abstract}

Keywords:

\section{Introduction}

Time table scheduling has been in human requirements since all thought of managing time effectively. It is widely used in schools, and other fields of teaching and working like crash courses, coaching center, training programs etc. In early days, time table scheduling was done manually with one single person or some group involved in task of scheduling it with their hands, which takes a lot of effort and time. While scheduling even the smallest constraints can take a lot of time and the cases are even more worse when the number of constraints or the amount of data to deal with increases. In such cases perfectly designed time table is reused for the whole generation without any changes, proving to be dull in such situations. Other cases thatcause problem is when the number of employers/workers are weak, resulting in the rescheduling of time table or they need to fill on empty seats urgently. They need to schedule their course to meet the need of current duration and facilities that are available to them. However, their schedule should meet the requirements of the new course additions and newly enrolled students to fresh batches. This may result in rescheduling the entire time table once again for its entire batches and to be scheduled in shortest possible time before the batch courses start. Another problem that occur when scheduling time table for exams. When multiple batches have their exam on same day, they need to be schedules effectively taking into account all problems related to the facilities that are available to conduct these exams simultaneously.

\section{Existing System}

In the existing system, each task is carried out manually and processing is a very tedious job. The Organization is not able to achieve its need in time and the results too may not be accurate. Due to all the manual maintenance, there are number of difficulties and drawbacks that exist in this system.

Drawbacks of the Existing System:

- Increased transaction leads to the increased source document and hence maintenance becomes difficult.
- If any student or staff entry is wrongly made then the maintenance becomes very difficult.

\section{Proposed System}

The proposed system is designed to be more efficient than the actual manual system. It invokes all base tasks that are now carried out manually, such as the forms transactions and reports which is added advantage. Description:

- Most colleges have a number of different courses and each course has ' $n$ ' number of subjects.

- Now there are limited faculties, and each faculty might be teaching more than one subjects.

- So now the time table needed to schedule all the faculty at provided time slots in such a way that their timings do not overlap and the time table schedule will make the best use of all faculty subject demands.

- We use a customized algorithm for this purpose.

- In our Timetable Generation algorithm we propose to utilize a timetable object.

- This object comprises of Classroom objects and the timetable forthem likewise a fitness score for the timetable.

- Fitness score relates to the quantity of crashes the timetable has regarding alternate calendars for all the different classes.

- Classroom object comprises of week objects. Week objects comprise of Days, Days comprises of Timeslots.

- Timeslot has an address in which a subject, student gathering going to that particular address and educator showing to the subject it is related will be shown.

- Also further on discussing, we have utilized composite configuration (design), which make it well extendable numerous obligations.

- In every obligation class the condition as determined in our inquiry is now checked between both the timetable objects. On the off chance that condition is fulfilled, there is a crash is avilable then score is augmented by one. 


\section{Project Design}

- E-R Diagram

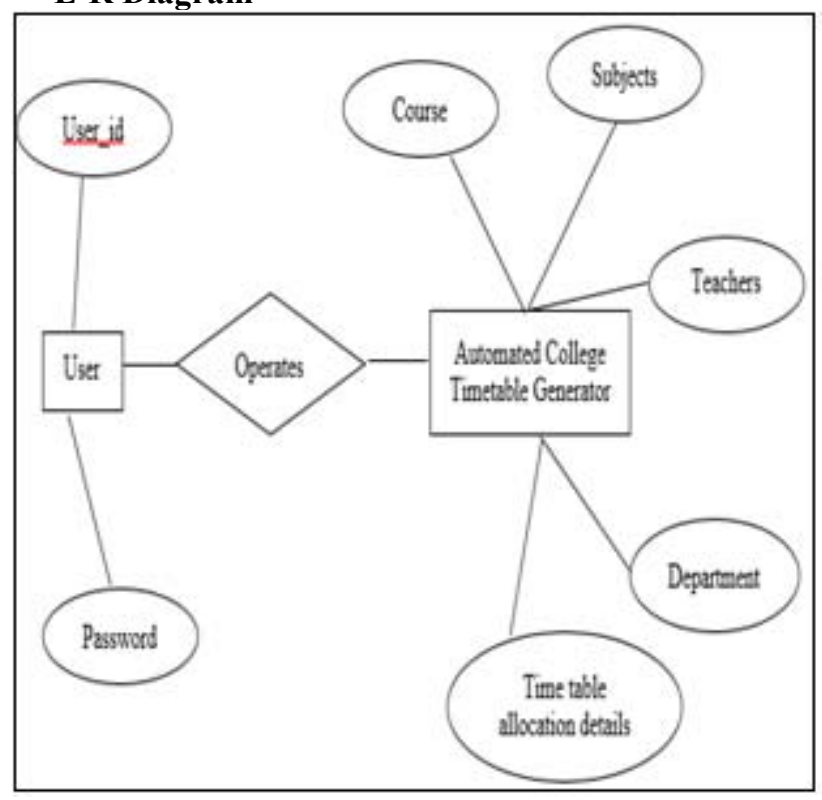

- Use-Case Diagram

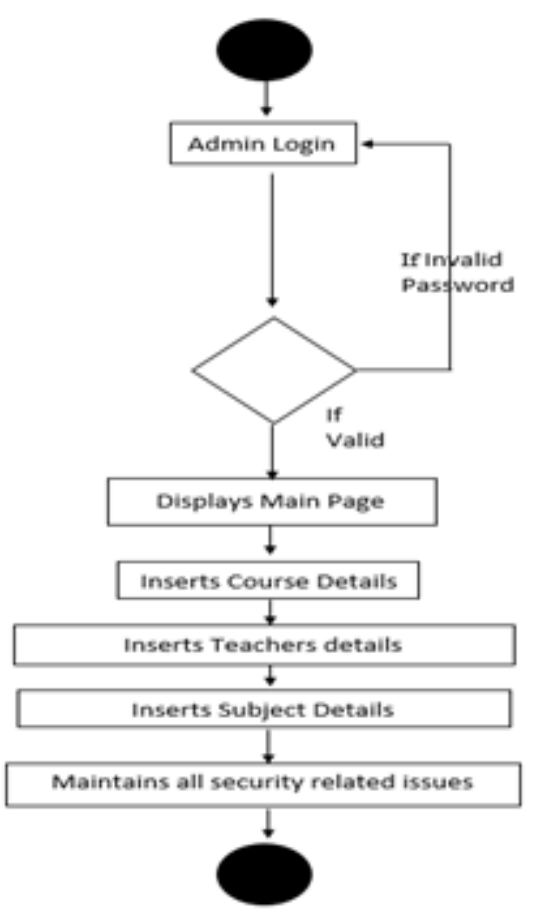

- Sequence-Diagram

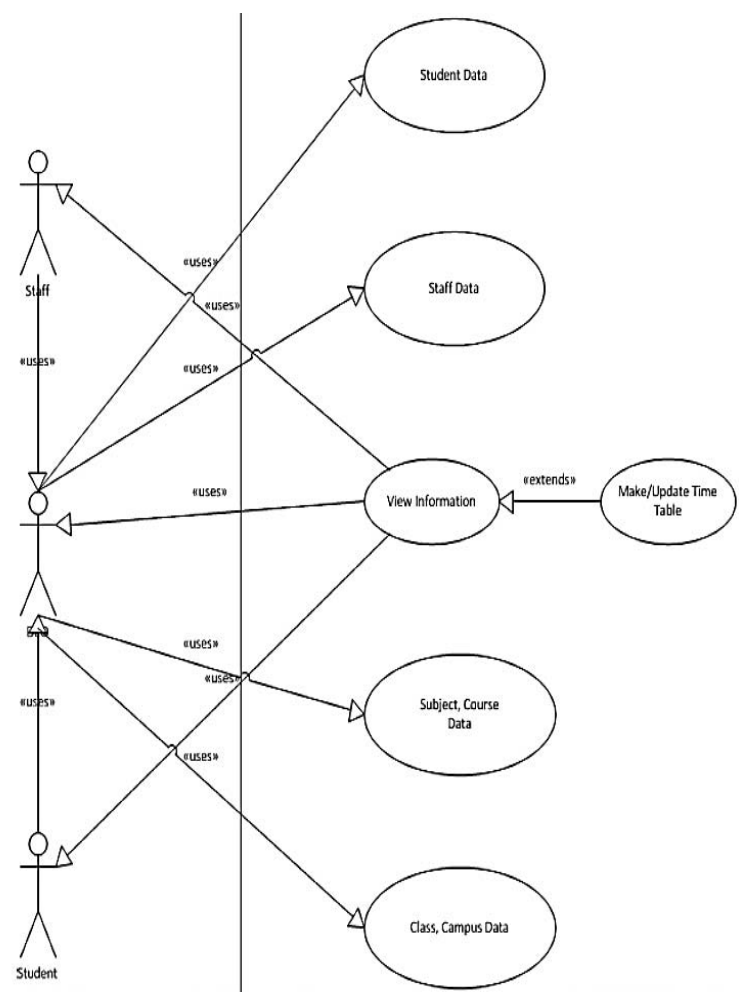

- Activity-Diagram

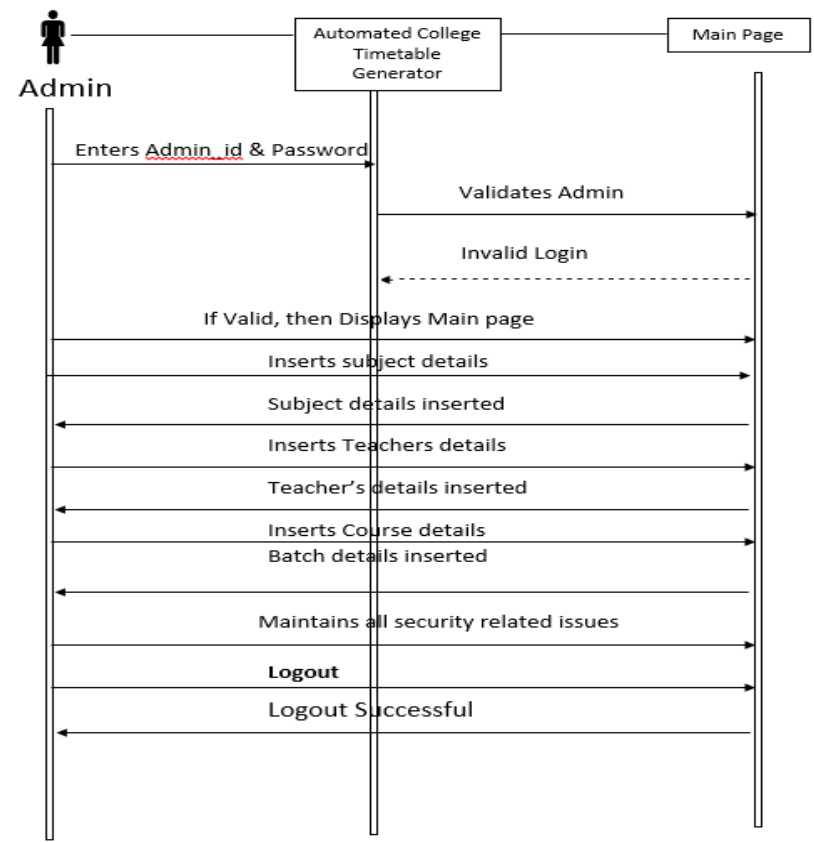

- Class Diagram

Volume 6 Issue 1, January 2017

www.ijsr.net 


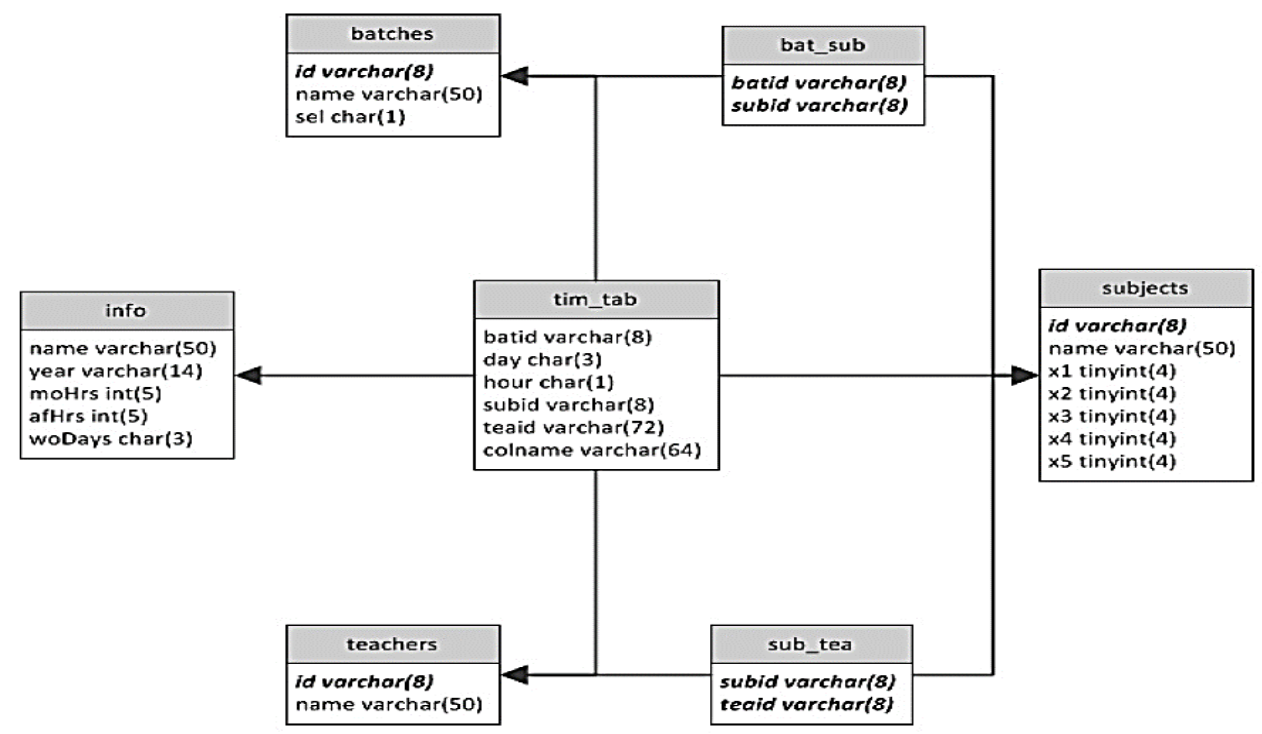

\section{System Architecture}

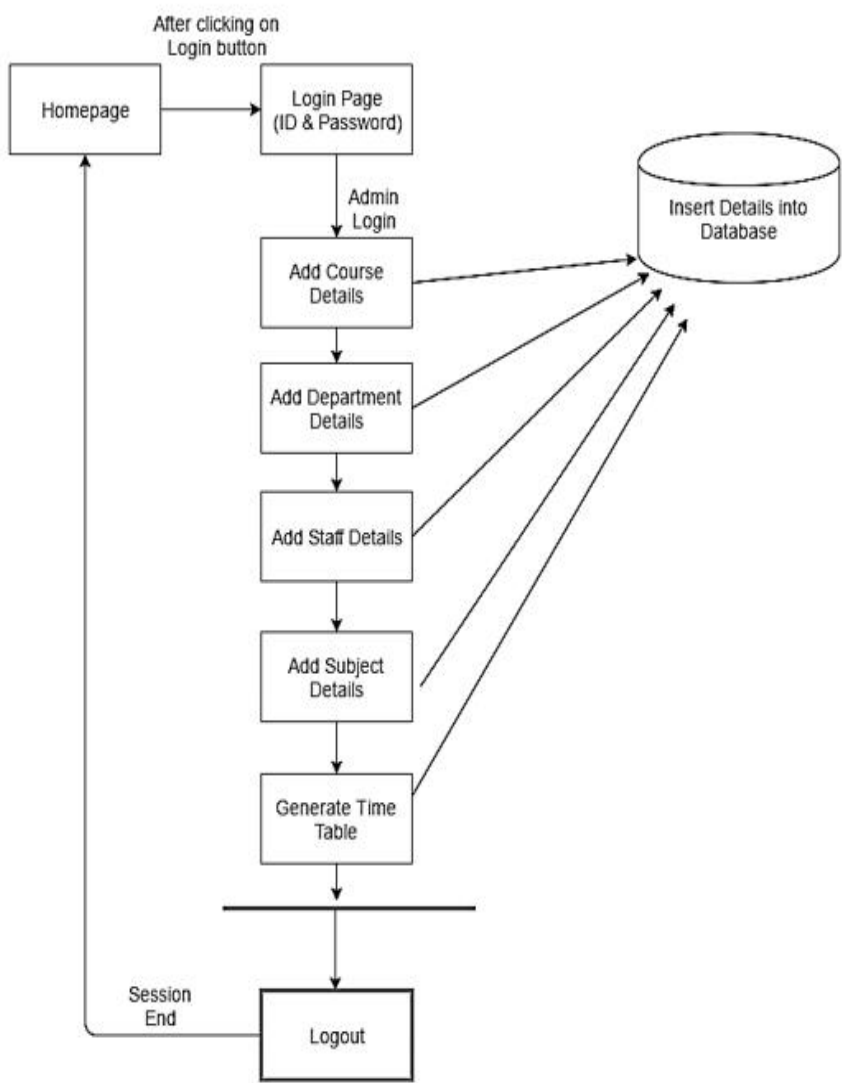

\section{Project Implementation}

The Project is loaded in Visual Studio 2010. We used Visual Studio for Design and coding of project. Created and maintained all databases into SQL Server 2008, in that we create tables, write query for store data or record of project.

\section{a)Hardware Requirement:-}

- Core i3 Processor Based Computer

- 1 GB-RAM

- 50 GB Hard Disk
b)Software Requirement:

- Windows 7 or higher

- Visual Studio 2010.

- SQL Server 2008.

\section{Overview of Technologies Used}

- Front End Technology: Microsoft .Net Framework

- Back End Technology: Microsoft SQL Server

- Middleware Technology: Active Data Objects.Net Overview

\section{Features}

1) Load Balancing:

Since the system will be available only the admin logs in the amount of load on server will be limited to time period of admin access.

2) Easy Accessibility:

Records can be easily accessed and store and other information respectively.

3) User Friendly: The Website will be giving a very user friendly approach for all users.

4) Efficient and reliable:

Maintaining the all secured and database on the server which will be accessible according the user requirement without any maintenance cost will be very efficient as compared to storing the customr data on the spreadsheet or in physically in the record books.

5) Easy maintenance:

Automated College Timetable Generator Website is design as easy way. So maintenance is also easy.

\section{Technical Feasibility}

In this step, we verify about the proposed systems are technically feasible or not. i.e., all the technologies required to develop the system are available readily or not.

Technical Feasibility determines whether the organization has the technology and skills necessary to carry the project 


\section{International Journal of Science and Research (IJSR) \\ ISSN (Online): 2319-7064 \\ Index Copernicus Value (2015): 78.96 | Impact Factor (2015): 6.391}

and how this should be obtained. The system can be feasible because of the following grounds:

All necessary technology exits to develop the system. This system is too flexible and it can be expanded further. This system can give guarantees of accuracy, ease of use, reliability and security of your data. This system can give instant response to inquire.

Our project is technically feasible because, all the technology needed for our project is readily available.

Operating System

Windows 7 or higher

Languages

Database System

: Asp.Net with C\# (.Net 2010)

Documentation Tool

MS-SQL Server 2008

MS - Word 2010

\section{Economic Feasibility}

Economically, this project is completely feasible because it requires no extra financial investment and with respect to time, it's completely possible to complete this project in 6 months .In this step, we verify the proposal which is more economical. We check the financial benefits of the new system with the investment. The new system is economically feasible only when the financial benefits are more than the investments and expenditure. Economic Feasibility determines whether the project goal can be within the resource limits allocated to it or not. It must determine whether it is compulsory to process with the entire project or whether the benefits obtained from the new system are not worth the costs. Financial benefits must be equal or exceed the costs.

Our project is economically feasible because the cost of development is very minimal when compared to financial benefits of the application.

\section{Operational Feasibilty}

In this step, we verify different operational factors of proposed systems like man-power, time etc., whichever solution uses less operational resources, is the best operationally feasible solution in which the solution should also be operationally possible to implement. Operational Feasibilitydetermines if the proposed system satisfied user objectives could be fitted into the current system operation.

- The methods of processing and presentation are completely accepted by the clients since they can meet all user requirements.

- The proposed system will not cause any problem under any circumstances.

Our project is operationally feasible sincethe time requirements and the personal requirements are satisfied. We are a team of four members and we worked on this project for three working months.

\section{Test Cases}

- User Login/Registration: To begin with login, user need to register by filling up basic registration details. There are multiple fields in registration page and every field has to fill by user. User cannot use character in the login id field.
- Admin Login: - Admin login id and password is kept compulsory fields, and if the admin id or password doesn't match then it will show an error message.

\section{Validation Criteria}

1) In each form, no field which is not null able should be left blank.

2) All numeric fields should be checked for non-numeric values. Similarly, text fields like names should not contain numeric characters.

3) All primary keys must be automatically generated to prevent all the users from entering any existing key.

4) Use of error handling for each Save, Edit, delete and few other important operations.

5) Whenever user Tabs out or Enter from a text box, the data should be validated and if it is invalid, focus should again be sent to the text box with proper message.

\section{Advantages}

- Faculty need not worry for time clashes.

- Authority now does not need to perform permutation and combination

- Authority can concentrate on other things rather than wasting their time on preparing Time-Table.

- Gives accurate information

- Simplifies the manual work

- It minimizes the documentation related work

- Provides up to date information

- Friendly Environment by providing warning messages.

\section{Disadvantages}

User has to format it a bit after it is prepared.

\section{Applications}

This system can be used by Schools and Colleges to create Time-Table.

\section{References}

[1] en.wikipedia.org

[2] http://msdn2.microsoft.com/en-us/default.aspx: This is a valuable online resource, and is a must for any developer using Microsoft tools.

[3] http://www.asp.net/

[4] http://ieeexplore.ieee.org/xpl/articleDetails.jsp?tp=\&arnu mber $=870307 \&$ queryText $\% 3$ DAutomated + Timetable $+\mathrm{G}$ eneration

[5] http://ieeexplore.ieee.org/xpl/articleDetails.jsp?tp=\&arnu mber $=1004507 \&$ queryText $\% 3$ DAutomated+Timetable + Generation

[6] http://ieeexplore.ieee.org/xpl/articleDetails.jsp?tp=\&arnu mber $=6427222 \&$ queryText\%3DTimetable+Generation

[7] http://ieeexplore.ieee.org/xpl/articleDetails.jsp?tp=\&arnu mber $=1490384 \&$ queryText $\% 3$ DTimetable+Generation

[8] http://docslide.us/documents/project-synopsis-forautomatic-timetable-generator.html 